\title{
Lokale behandeling bij het primair gemetastaseerd prostaatcarcinoom
}

\author{
Liselotte M. S. Boevé ${ }^{1,2} \cdot$ Maarten C. C. M. Hulshof ${ }^{3}$ André N. Vis² Peter de Vries $^{4} \cdot$ R. Jeroen A. van Moorselaar ${ }^{2}$. \\ Wim P. J. Witjes ${ }^{5}$ Paul C. M. S. Verhagen ${ }^{6}$. George van Andel ${ }^{1}$
}

Published online: 11 September 2019

(c) The Author(s) 2019

\section{Samenvatting}

Nog steeds heeft een substantieel deel van de patiënten met prostaatcarcinoom reeds metastasen ten tijde van het stellen van de diagnose. Uit recente literatuur blijkt dat bij deze patiënten lokale radiotherapie van de prostaat geadviseerd dient te worden, mits zij een lage metastaselast hebben (volgens de CHAARTED-criteria). In dit artikel wordt de beschikbare literatuur hieromtrent besproken.

Trefwoorden prostaatkanker $\cdot$ metastasen $\cdot$ lokale behandeling $\cdot$ radiotherapie

\section{Local therapy in primary metastatic prostate cancer}

\begin{abstract}
A substantial proportion of patients with prostate cancer have metastases at the time of diagnosis. Recent literature suggests that local radiotherapy to the prostate should be advised in these patients, provided they have a low metastasic burden (as defined by the CHAARTED criteria). This article discusses the available literature.
\end{abstract}

Keywords prostate cancer $\cdot$ metastases $\cdot$ local treatment $\cdot$ radiotherapy

\section{Introductie}

Hoewel het testen op prostaatspecifiek antigeen (PSA) heeft geleid tot eerdere detectie van prostaatcarcinoom, blijkt uit de Nederlandse PROZIB-database (Prostaatkanker Zorg In Beeld) dat nog steeds $15,8 \%$ van de patiënten zich al ten tijde van de diagnose prostaatcarcinoom presenteren met

drs. Liselotte M. S. Boevé

1.boeve@olvg.nl

1 afdeling Urologie, OLVG, Amsterdam, Nederland

2 afdeling Urologie, Amsterdam Universitair Medische Centra, Locatie VUmc, Amsterdam, Nederland

3 afdeling Radiotherapie, Amsterdam Universitair Medische Centra, Locatie VUmc, Amsterdam, Nederland

4 afdeling Urologie, Zuyderland Medisch Centrum, Heerlen, Nederland

5 CuraTrial SMO \& Research BV, Arnhem, Nederland

6 afdeling Urologie, Erasmus Medisch Centrum, Rotterdam, Nederland ossaal gemetastaseerde ziekte. De standaardbehandeling voor gemetastaseerde ziekte was tot voor kort systemische behandeling met androgeendeprivatietherapie (ADT), een behandeling die tegenwoordig bij patiënten vaak initieel wordt gecombineerd met docetaxel of abiraterone [1-3]. De behandeling van de primaire prostaattumor was geen standaardpraktijk bij patiënten met primair gemetastaseerde ziekte. Behandeling van de primaire prostaattumor werd alleen ingezet ter palliatie van lokale problemen.

In 2004 werd de eerste gerandomiseerde gecontroleerde trial (RCT) naar de lokale behandeling van de prostaat bij patiënten met primair gemetastaseerd prostaatcarcinoom (mPCa) in Nederland geïnitieerd. De hypothese dat lokale behandeling van invloed zou kunnen zijn op de overleving was mede gebaseerd op de resultaten van de Bolla-studies, en de EORTC/SWOG-studies naar de overlevingswinst van een cytoreductieve nefrectomie [4]. Nadien heeft ook de Britse STAMPEDE-trial een arm geïncludeerd waarin gekeken werd naar het effect van lokale behandeling met radiotherapie [5]. De resultaten van deze RCT's hebben geleid tot nieuwe belangrijke inzichten, die wij graag in dit artikel met u delen. 


\section{Retrospectieve studies}

In de loop der jaren zijn er meerdere retrospectieve, grotendeels cohortstudies naar het effect van lokale therapie in de gemetastaseerde setting gepubliceerd met patiënten met een verschillende uitgebreidheid van mPCa. In die onderzoeken bestond de primaire behandeling uit brachytherapie, radiotherapie of radicale prostatectomie. Een voorbeeld hiervan is het rapport dat Leyh-Bannurah et al. publiceerden [6]. Zij voerden een voor propensity score gematchte analyse uit op 13.692 patiënten met primair gemetastaseerd prostaatcarcinoom uit de SEER (Surveillance, Epidemiology, and End Results) databank, een Amerikaanse databank waarin patiënten met verschillende vormen van kanker gevolgd en geregistreerd worden. Van de 13.692 patiënten ondergingen 313 patiënten een radicale prostatectomie (RP) en 161 kregen brachytherapie op de prostaat. De onderzoekers stelden vast dat toevoeging van zowel een prostatectomie als brachytherapie aan ADT leidde tot lagere percentages kankerspecifieke mortaliteit (CSS) dan wanneer er geen lokale behandeling werd gegeven (65\% voor RP en $52 \%$ voor $\mathrm{RT})$. Andere rapportages lieten vergelijkbare uitkomsten zien [7-11].

In deze retrospectieve onderzoeken is echter, ondanks zorgvuldige statistische modellering, een algemeen aanwezige selectiebias in het voordeel van gezondere patiënten met een lagere tumorlast waarschijnlijk, vooral omdat lokaal behandelde patiënten in deze rapportages een zeer klein percentage van het gehele cohort vormen.

Gegevens van verschillende onderzoeken suggereerden dat patiënten met gemetastaseerd prostaatcarcinoom het meeste voordeel ondervinden van lokale behandeling naarmate de tumoreigenschappen gunstiger zijn. Löppenberg et al. gebruikten gegevens van de Amerikaanse National Cancer DataBase en includeerden 15.501 patiënten met M1a-c mPCa [9]. Van hen ondergingen 1.470 patiënten lokale behandeling (brachytherapie, EBRT of RP). De onderzoekers gebruikten voorspellende factoren van een multivariabele Cox-regressieanalyse om het totale mortaliteitsrisico te voorspellen. $\mathrm{Zij}$ constateerden dat het gunstige effect van lokale behandeling op de mortaliteit progressief afnam, naarmate het voorspelde totale mortaliteitsrisico toenam en concludeerden dat patiënten met een betrekkelijk lage tumorlast en een goede algehele gezondheidsstatus het meeste voordeel leken te hebben.

Pompe et al. publiceerden onlangs een update van de gegevens van de SEER-databank [12]. Deze update gaf meer inzicht in de invloed van M1-substadia en de PSAspiegels op baseline, op het effect van lokale behandeling bij mPCa. Zij voerden multivariabele regressieanalysen uit met concurrerende risico's na 1:2-matching van de propensity score en vonden een significant voordeel voor lokale behandeling bij M1a-patiënten. Bij M1b-patiënten werd het overlevingsvoordeel gemoduleerd door hun baseline-PSA, waarna bleek dat bij deze patiënten lokale behandeling niet leidde tot een verbetering van kankerspecifieke overleving als hun baseline-PSA $>60 \mathrm{ng} / \mathrm{ml}$ was. Bij patiënten met M1c-ziekte leidde lokale behandeling niet tot kankerspecifiek overlevingsvoordeel, ongeacht de PSA-waarde op baseline.

Hoewel een groot aantal recente retrospectieve onderzoeken duiden op een gunstig effect van lokale behandeling bij patiënten met een lage metastaselast, werd dit niet in alle onderzoeken vastgesteld. Steuber et al. rapporteerden in een prospectief patiënt-controleonderzoek met 83 patiënten dat degenen met laagvolume botmetastasen en gunstige kenmerken op baseline die RP ondergingen geen significant betere totale overleving hadden dan patiënten die de beste systemische behandeling $(p=0,3)$ kregen[13]. In dit onderzoek was echter maar een klein aantal patiënten geïncludeerd en het betreft chirurgische en geen radiotherapeutische behandeling.

Om meer duidelijkheid te scheppen, was er veel behoefte aan niveau 1-bewijs uit RCT's.

\section{Gerandomiseerde studies - HORRAD}

Recentelijk zijn de resultaten van de Nederlandse HORRAD-studie gepubliceerd [4]. Tussen 2004 en 2014 zijn in totaal 432 patiënten geïncludeerd in 28 Nederlandse centra. De inclusiecriteria waren een histologisch bewezen adenocarcinoom van de prostaat, een PSA van meer dan $20 \mathrm{ng} / \mathrm{ml}$ en ossale metastasen op een botscan. Patiënten werden gerandomiseerd tussen ADT met externe radiotherapie op de prostaat (radiotherapiegroep) of alleen ADT (controlegroep). Het primaire eindpunt was de totale overleving. Het mediane PSA was $142 \mathrm{ng} / \mathrm{ml}$ en $67 \%$ van de patiënten had meer dan vijf ossale metastasen (tab. 1). De mediane follow-up bedroeg 47 maanden. De mediane totale overleving bedroeg 45 maanden $(95 \%-\mathrm{BI}=40,4-49,6)$ in de groep die was behandeld met radiotherapie en 43 maanden $(95 \%$-BI $=32,6-53,4)$ in de controlegroep $(p=0,4)$. Er werd geen significant verschil gevonden in de totale overleving $(\mathrm{HR}=0,90 ; 95 \%-\mathrm{BI}=0,70-1,14 ; p=0,4)$. De mediane tijd tot PSA-progressie in de groep met radiotherapie was 15 maanden $(95 \%-\mathrm{BI}=11,8-18,2)$ tegenover 12 maanden $(95 \%-\mathrm{BI}=10,6-13,4)$ in de controlegroep. De ruwe hazardratio $(0,78 ; 95 \%-\mathrm{BI}=0,63-0,97)$ van de tijd tot PSAprogressie was wel statistisch significant $(p=0,02)$ in het voordeel van de groep die radiotherapie kreeg. Er is gekeken naar het verschil in uitkomsten bij patiënten in verschillende subgroepen. Helaas zijn de patiënten van deze populatie niet te classificeren volgens de CHAARTED-criteria, omdat het aantal metastasen gescoord werd in drie categorieën $(<5,5-15$ en $>15)$ en we niet geënformeerd 
Tabel 1 Baselinekarakteristieken van de HORRAD- en STAMPEDE-studie

\begin{tabular}{|c|c|c|c|c|}
\hline & \multicolumn{2}{|l|}{ HORRAD } & \multicolumn{2}{|l|}{ STAMPEDE } \\
\hline & $\begin{array}{l}\text { ADT + radiotherapie } \\
n=216\end{array}$ & $\begin{array}{l}\text { ADT alleen } \\
n=216\end{array}$ & $\begin{array}{l}\mathrm{ADT}+\text { radiotherapie } \\
n=1.032\end{array}$ & $\begin{array}{l}\text { ADT alleen } \\
n=1.032\end{array}$ \\
\hline leeftijd in jaren (range) & $67(62-71)$ & $67(61-71)$ & $68(63-73)$ & $68(63-73)$ \\
\hline \multicolumn{5}{|l|}{ WHO Performance status } \\
\hline-0 & $187(87 \%)$ & $176(82 \%)$ & $734(71 \%)$ & $732(71 \%)$ \\
\hline$-1-3$ & $29(13 \%)$ & $40(18 \%)$ & $298(29 \%)$ & $297(29 \%)$ \\
\hline \multicolumn{5}{|c|}{ PSA concentratie voor ADT (ng/ml) } \\
\hline - mediaan (range) & $125(8-14.000)$ & $149(4-6.991)$ & $97(33-313)$ & $98(30-316)$ \\
\hline - Q1 & 48 & 50 & 33 & 30 \\
\hline$-\mathrm{Q} 3$ & 433 & 483 & 313 & 316 \\
\hline \multicolumn{5}{|l|}{ gleason somscore } \\
\hline$-<7$ & $73(34 \%)$ & $71(33 \%)$ & $172(18 \%)$ & $173(17 \%)$ \\
\hline$-8-10$ & $142(66 \%)$ & $144(67 \%)$ & $810(82 \%)$ & $820(83 \%)$ \\
\hline - onbekend & 1 & 1 & 50 & 36 \\
\hline \multicolumn{5}{|l|}{ T stadium } \\
\hline$-\mathrm{T} 1$ & $7(3 \%)$ & $5(3 \%)$ & $12(1 \%)$ & $12(1 \%)$ \\
\hline$-\mathrm{T} 2$ & $33(15 \%)$ & $20(9 \%)$ & $89(9 \%)$ & $84(9 \%)$ \\
\hline$-\mathrm{T} 3$ & $125(58 \%)$ & $128(60 \%)$ & $603(63 \%)$ & $585(62 \%)$ \\
\hline$-\mathrm{T} 4$ & $51(24 \%)$ & $59(28 \%)$ & $246(26 \%)$ & $260(28 \%)$ \\
\hline - onbekend & 0 & 4 & 82 & 88 \\
\hline \multicolumn{5}{|l|}{ ossale metastasen } \\
\hline$-<5$ & $89(41 \%)$ & $71(33 \%)$ & & \\
\hline$-5-15$ & $53(25 \%)$ & $65(30 \%)$ & & \\
\hline$->15$ & $74(34 \%)$ & $80(37 \%)$ & & \\
\hline \multicolumn{5}{|l|}{ metastaselast } \\
\hline - laag & & & $410(43 \%)$ & $409(42 \%)$ \\
\hline- hoog & & & $553(57 \%)$ & $567(58 \%)$ \\
\hline - niet geclassificeerd & & & 69 & 53 \\
\hline \multicolumn{5}{|l|}{ lokalisatie metastasen } \\
\hline- bot & & & $917(89 \%)$ & $919(89 \%)$ \\
\hline - lever & & & $19(2 \%)$ & $23(2 \%)$ \\
\hline - long & & & $48(5 \%)$ & $42(4 \%)$ \\
\hline - extraregionale klieren & & & $304(29 \%)$ & $294(29 \%)$ \\
\hline - elders & & & $33(3 \%)$ & $35(3 \%)$ \\
\hline
\end{tabular}

Data zijn mediaan (IQR) of aantal patiënten (\%). PSA prostaatspecifiek antigeen. $Q 1$ en $Q 3$ onder- resp. bovengrens van de IQR WHO performance status 0 zonder beperkingen, 1-3 beperkt in dagelijkse bezigheden in oplopende mate bij hogere score

zijn over de aanwezigheid van viscerale metastasen, omdat disseminatieonderzoek enkel bestond uit de op dat moment gebruikelijke botscan. In een exploratieve subgroepanalyse van patiënten met minder dan vijf botmetastasen werd wel een trend naar overlevingsvoordeel gezien met vergelijkbare HR's als in de STAMPEDE-trial $(\mathrm{HR}=0,68$ $(0,42-1,10)$ bij $<5$ metastasen en HR $=1,06(0,80-1,39)$ bij $>5$ metastasen). Dit verschil is echter niet statistisch significant, waarschijnlijk door het relatief kleine aantal patiënten.

Bij deze patiënten in een palliatieve setting is de kwaliteit van leven uiteraard van groot belang. Alle patiënten hebben kwaliteit-van-levenvragenlijsten ingevuld voor de start van de behandeling en na 3, 6, 12 en 24 maanden. Hieruit blijkt dat er sprake is van passagère mictieklachten bij de patiënten die aanvullend radiotherapie gekregen hebben. $\mathrm{Na}$ 6 maanden waren de scores op dit vlak weer terug naar de uitgangssituatie. Wel rapporteerden zij meer darmproblemen, waarbij er ook na 24 maanden nog een verschil was in vergelijking tot de controlegroep. De algehele kwaliteit van leven wordt niet nadelig beïnvloed door bestraling. Uitgebreidere gegevens over de kwaliteit-van-levenanalyses worden binnenkort voor publicatie aangeboden.

Het is belangrijk ons te realiseren dat er in dit cohort sprake is van een grote tumorlast met een hoog mediaan PSA-gehalte, en van patiënten met uitgebreid ossaal gemetastaseerde ziekte. De conclusie op basis van deze trial moet dan ook zijn dat bij ongeselecteerde patiënten met primair 
ossaal gemetastaseerd prostaatcarcinoom lokale behandeling van de prostaat niet leidt tot een betere overleving.

\section{Gerandomiseerde studies - STAMPEDE}

Aan de prospectieve, multi-arm gerandomiseerde Britse STAMPEDE-studie is in 2013 arm $\mathrm{H}$ geïnitieerd, waarbij lokale radiotherapie op de prostaat toegevoegd werd aan ADT bij patiënten met de novo gemetastaseerde ziekte [5]. Er werden 2.061 patiënten gerandomiseerd tussen standaardzorg (levenslang ADT, waarbij vanaf december 2015 ook upfront docetaxel toegevoegd mocht worden) en standaardzorg in combinatie met lokale radiotherapie. Het mediane PSA-gehalte in deze studiepopulatie was $97 \mathrm{ng} / \mathrm{ml}$ en $52 \%$ van de patiënten had een hoge metastaselast volgens de CHAARTED-criteria ( $\geq 4$ ossale metastasen waarvan minimaal 1 buiten het axiale skelet of bekken, of viscerale metastasen), $40 \%$ van de patiënten had een lage metastaselast (tab. 1). Na een mediane follow-up van 37 maanden was de totale overleving in de gehele groep niet statistisch significant verschillend $(\mathrm{HR}=0,92 ; 95 \%$ $\mathrm{BI}=0,80-1,06 ; p=0,226)$.

De onderzoekers definieerden vooraf een subgroep voor een analyse die was gebaseerd op de tot dan toe bekende retrospectieve uitkomsten. De resultaten van deze analyse suggereerden dat er een voordeel zou zijn voor patiënten met een lage metastaselast. Omdat deze subgroep van tevoren gedefinieerd was en het aantal subgroepanalyses sterk beperkt is, zijn de resultaten betekenisvol. Het vooraf definiëren van een subgroep voorkomt namelijk dat er door een statisticus gezocht wordt tot er een statistisch significant verschil gevonden wordt.

Deze subgroepanalyse toonde dat bij bestraalde patiënten met een lage metastaselast $(n=819)$ een statistisch significante verbetering van de driejaarsoverleving was van $73 \%$ naar $81 \%(\mathrm{HR}=0,68 ; 95 \%-\mathrm{BI}=0,52-0,9 ; p=0,007)$. Dit verschil werd niet gezien bij patiënten met een hoge metastaselast $(54 \%$ vs. $53 \%$; $\mathrm{HR}=1,07 ; 95 \%$-BI $=0,9-1,28$; $p=0,42)$.

\section{Meta analyse - STAMPEDE EN HORRAD}

De resultaten van beide eerder genoemde RCT's zijn samengevoegd in een meta-analyse [14]. Hierbij werden analyses gedaan met de individuele patiëntendata van in totaal 2.126 patiënten. De gecombineerde resultaten van deze studies lieten ook geen verbetering zien met radiotherapie op de algehele overleving $(\mathrm{HR}=0,92$; $95 \%$ $\mathrm{BI}=0,81-1,04 ; p=0,195)$, wel in biochemische progressie $\left(\mathrm{HR}=0,74 ; 95 \%-\mathrm{BI}=0,67-0,82 ; p=0,94 \cdot 10^{-8}\right)$. Het effect van radiotherapie op de prostaat varieerde met de metastaselast. Er werd een significante verbetering in de driejaarsoverleving gevonden van $7 \%$ in de subgroep van mannen met minder dan vijf ossale metastasen $(\mathrm{HR}=0,73$; $95 \%-\mathrm{BI}=0,58-0,92 ; p=0,0071)$.

\section{Beschouwing}

Er zijn wereldwijd nog meer studies uitgevoerd waarin patiënten geïncludeerd worden ter beantwoording van de vraag wat het effect van lokale therapie is in de gemetastaseerde setting, dan in dit artikel zijn beschreven. Wat interessant zal zijn, is of lokale behandeling met radicale prostatectomie tot dezelfde resultaten zal leiden als lokale behandeling met radiotherapie. Aangezien het werkingsmechanisme achter het effect van lokale radiotherapie nog niet opgehelderd is, en het goed zou kunnen dat de immuunrespons die radiotherapie teweegbrengt van invloed is op de mate van effect, is het de vraag of we dezelfde resultaten zullen zien na lokale behandeling middels radicale prostatectomie. Daarnaast wordt in meerdere studies bekeken wat het effect zal zijn van de behandeling van de oligometastasen zelf, naast behandeling van de primaire tumor.

Tegenwoordig berust het disseminatieonderzoek van patiënten met PCa steeds meer op nieuwe beeldvormende modaliteiten, zoals prostaatspecifiek membraanantigeen (PSMA) positronemissietomografie/computertomografie (PET/CT) scans. Het is een feit dat door de toepassing van deze moderne beeldvormende technieken metastasen en dus ook oligometastasen steeds eerder en vaker zullen worden gedetecteerd, zoals ook besproken in het artikel van Oprea-Lager en Comans [15]. Verdere discussie is noodzakelijk over de vraag hoe de bevindingen bij deze nieuwe beeldvormende modaliteiten zich verhouden tot de tot nu toe gepubliceerde RCT's, waarbij stadiumbepaling plaatsvond aan de hand van botscintigrafie en conventionele CT-scans.

Leyten et al. publiceerden een mooi en volledig overzicht over de beschikbare aanvullende systemische behandelingen bij gemetastaseerd prostaatcarcinoom [16]. In de groep patiënten met een hoge metastaselast ten tijde van de diagnose geeft abiraterone plus prednison als toevoeging aan ADT een vergelijkbare overlevingswinst met zes kuren docetaxel naast ADT. Gezien de kortere behandelduur met dientengevolge ook minder bijwerkingen en de aanzienlijk lagere kosten, is het advies deze patiënten initieel te behandelen met docetaxel naast ADT.

Alles overwegende kunnen we concluderen dat het advies moet zijn om patiënten met een primair ossaal gemetastaseerd prostaatcarcinoom met een lage metastaselast primair lokaal te behandelen met radiotherapie op de prostaat naast ADT en bij patiënten met een hoge metastaselast zes kuren docetaxel toe te voegen aan behandeling met ADT. 


\section{Conclusie}

Afgaand op de nu beschikbare literatuur, dient lokale radiotherapie van de prostaat naast ADT bij patiënten met primair gemetastaseerd prostaatcarcinoom met een lage metastaselast (volgens de CHAARTED-criteria) geadviseerd te worden. Dit advies is ook opgenomen in de meest recente EAU Guideline voor prostaatcarcinoom.

Open Access This article is distributed under the terms of the Creative Commons Attribution 4.0 International License (http:// creativecommons.org/licenses/by/4.0/), which permits unrestricted use, distribution, and reproduction in any medium, provided you give appropriate credit to the original author(s) and the source, provide a link to the Creative Commons license, and indicate if changes were made.

\section{Literatuur}

1. Cornford P, Bellmunt J, Bolla M, Briers E, Santis M de, Gross T, et al. EAU-ESTRO-SIOG guidelines on prostate cancer. Part II: treatment of relapsing, metastatic, and castration-resistant prostate cancer. Eur Urol. 2017;71(4):630-42.

2. Ryan CJ, Smith MR, Fizazi K, Saad F, Mulders PFA, Sternberg CN, et al. Abiraterone acetate plus prednisone versus placebo plus prednisone in chemotherapy-naive men with metastatic castration-resistant prostate cancer (COU-AA-302): Final overall survival analysis of a randomised, double-blind, placebo-controlled phase 3 study. Lancet Oncol. 2015;16(2):152-60.

3. Kyriakopoulos CE, Chen Y, Carducci MA, Liu G, Jarrard DF, Hahn NM, et al. Chemohormonal therapy in metastatic hormone-sensitive prostate cancer: long-term survival analysis of the randomized phase III E3805 CHAARTED trial. J Clin Oncol. 2018;36(11):1080-7.

4. Boevé LMS, Hulshof MCCM, Vis AN, Zwinderman AH, Twisk JWR, Witjes WPJ, et al. Effect on survival of androgen deprivation therapy alone compared to androgen deprivation therapy combined with concurrent radiation therapy to the prostate in patients with primary Bone metastatic prostate cancer in a prospective Randomised clinical trial. Eur Urol. 2019;75(3):410-8.

5. Parker CC, James ND, Brawley CD, Clarke NW, Hoyle AP, Ali A, et al. Radiotherapy to the primary tumour for newly diagnosed, metastatic prostate cancer (STAMPEDE): a randomised controlled phase 3 trial. Lancet. 2018;392(10162):2353-66.

6. Leyh-Bannurah S-R, Gazdovich S, Budäus L, Zaffuto E, Briganti A, Abdollah F, et al. Local therapy improves survival in metastatic prostate cancer. Eur Urol. 2017;72:118-24.

7. Culp SH, Schellhammer PF, Williams MB. Might men diagnosed with metastatic prostate cancer benefit from definitive treat- ment of the primary tumor? A SEER-based study. Eur Urol. 2014;65:1058-66.

8. Satkunasivam R, Kim AE, Desai M, Nguyen MM, Quinn DI, Lewinger JP, et al. Radical prostatectomy or external beam radiation therapy versus no local therapy for survival benefit in metastatic prostate cancer-a SEER-Medicare analysis. J Urol. 2015; 194:378-85.

9. Löppenberg B, Dalela D, Karabon P, Sood A, Sammon JD, Meyer CP, et al. The impact of local treatment on overall survival in patients with metastatic prostate cancer on diagnosis: a national cancer data base analysis. Eur Urol. 2017;72:14-9.

10. Gratzke C, Engel J, Stief CG. Role of radical prostatectomy in metastatic prostate cancer: data from the munich cancer registry. Eur Urol. 2014;66:602-3.

11. Parikh RR, Byun J, Goyal S, Kim IY. Local therapy improves overall survival in patients with newly diagnosed metastatic prostate cancer. Prostate. 2017;77:559-72.

12. Pompe RS, Tilki D, Preisser F, Bandini M, Marchioni M, Gild P, et al. Survival benefit of local versus no local treatment for metastatic prostate cancer. Impact of baseline PSA and metastatic substages. Prostate. 2018;78:753-7.

13. Steuber T, Berg KD, Røder MA, Brasso K, Iversen P, Huland H, et al. Does cytoreductive prostatectomy really have an impact on prognosis in prostate cancer patients with low-volume bone metastasis? Results from a prospective case-control study. Eur Urol Focus. 2017;3(6):646-9.

14. Burdett S, Boevé LM, Ingleby FC, Fisher DJ, Rydzewska LH, Vale CL, et al. Prostate radiotherapy for metastatic hormone-sensitive prostate cancer: a STOPCAP systematic review and Metaanalysis. Eur Urol. 2019;76:115-24.

15. Oprea-Lager DE, Comans EFI. Nieuwe beeldvormende technieken bij de diagnostiek van het prostaatcarcinoom. Tijdschr Urol. 2019;8(5). In druk.

16. Leyten GHJM, Oort IM van, Bergman AM. Op metastasen gerichte behandeling van prostaatcarcinoom. Tijdschr Urol. 2019;6. In druk.

drs. Liselotte M.S. Boevé uroloog

dr. Maarten C.C.M. Hulshof radiotherapeut

dr. André N. Vis uroloog

dr. Peter de Vries uroloog

prof. dr. R. Jeroen A. van Moorselaar uroloog

dr. Paul C.M.S. Verhagen uroloog

dr. George van Andel uroloog 